\title{
KONDO SEMICONDUCTOR CeNiSn
}

\section{AUTHOR(S):}

Takabatake, T.; Nakamoto, G.; Tanaka, H.; Fujii, H.; Nishigori, S.; Suzuki, T.; Fujita, T.; ... Oguro, I.; Kurisu, M.; Menovsky, A. A.

\section{CITATION:}

Takabatake, T.... [et al]. KONDO SEMICONDUCTOR CeNiSn. 物性研究 1993, 60(5): 586-601

\section{ISSUE DATE:}

1993-08-20

URL:

http://hdl.handle.net/2433/95141

RIGHT: 
講義ノート

$$
\begin{aligned}
& \text { サブゼミ 磁 性 } \\
& \text { テーマ「近藤半導体 CeNiSn」 }
\end{aligned}
$$

講師

高畠 敏郎 先生

広島大学 総合科学部

近藤格子化合物は、価数変動や重い電子的挙動などの特異な物性を示すため、発見以 来、盛んに研究されています。そのなかで $\mathrm{Ce}$ 化合物は磁気秩序の有無にかかわらず低温 では金属的に振る舞います。しかしながら、CeNiSnの電気抵抗は低温で半導体的に増加 を示します。CeNiSn は他にも比熱、磁化率、加圧下での抵抗等でも異常がみられるとい うような大変興味深い物質です。

今回のサブゼミでは $\mathrm{f}$ 電子系のこのような「近藤半導体 CeNiSn」についてお話して いただく予定です。

内容的には講義のみとなりますが、この分野での現状を積極的に学習し、活発な質疑 応答での討論を期待します。

\author{
世話人 光吉 成輝 \\ 山口大学 理学部物理
}




\title{
近藤半藤体CeNiSn \\ 広島大学総合科学部 \\ 高畠敏郎
}

\section{KONDO SEMICONDUCTOR CeNiSn}

\author{
T. Takabatake ${ }^{1}$, G. Nakamoto ${ }^{1}$, H. Tanaka ${ }^{1}$, H. Fujii ${ }^{1}$, S. Nishigori ${ }^{2}$, \\ T. Suzuki ${ }^{2}$, T. Fujita, ${ }^{2}$ M. Ishikawa ${ }^{3}$, I. Oguro ${ }^{3}$, M. Kurisu ${ }^{4}$ and \\ A.A. Menovsky 5 \\ ${ }^{1}$ Faculty of Integrated Arts and Sciences, Hiroshima University, Hiroshima \\ 730, Japan \\ ${ }^{2}$ Faculty of Science, Hiroshima University, Higashi-Hiroshima 724, Japan \\ 3Institute for Solid State Physics, University of Tokyo, Tokyo 106, Japan \\ ${ }^{4}$ Faculty of Engineering, Iwate University, Morioka 020, Japan \\ 5 Van der Waals-Zeeman Laboratorium, Universiteit van Amsterdam, 1018 XE, \\ Amsterdam, The Netherlands
}

\section{INTRODUCTION}

Since the discovery of semiconducting behavior of $\mathrm{SmB}_{6}$ in 1969,1 the formation of a small energy gap in $4 \mathrm{f}$-electron systems has been the subject of intensive studies. The presence of energy gap of several $10 \mathrm{~K}$ was found in valence-fluctuating (VF) compounds gold SmS, TmSe and $\mathrm{YbB}_{12}$ with cubic structures. ${ }^{2-4} \mathrm{~A}$ simple picture of these systems is that the hybridization of the $4 \mathrm{f}$ electron states and the conduction band leads to the small gap at the Fermi level. 5 However, the detailed mechanism of the gap formation remains unsettled. Recently, CeNiSn has been found to be the first example of a cerium compound showing the behavior of a small-gapped semiconductor. ${ }^{6}$ From the activation-type resistivity, the gap energy $\mathrm{E}_{\mathrm{g}}$ was estimated to be $6 \mathrm{~K}$. This compound crystallizes in an orthorhombic structure $\left(\operatorname{Pn} 2_{1} a\right),{ }^{7}$ which is closely related to the $\varepsilon$-TiNiSi type structure. Subsequently, similar gap formation has been found in $\mathrm{Ce}_{3} \mathrm{Pt}_{3} \mathrm{Bi}_{4}$ and $\mathrm{CeRhSb}, 8,9$ where the values of $E_{g}$ are 70 and $8 \mathrm{~K}$, respectively. The latter crystallizes in the same type of structure as $\mathrm{CeNiSn}$, whereas the former in the cubic $\mathrm{Y}_{3} \mathrm{Au}_{3} \mathrm{Sb}_{4}$-type structure. These findings have renewed the interest in the problem of the insulating ground state of the Kondo lattice. ${ }^{10,11}$

In this article, we review the experimental studies of the transport, magnetic and thermal properties of CeNiSn. ${ }^{12-17}$ The results obtained on single crystalline samples demonstrate that an anisotropic gap opens in the heavy-fermion bands as temperature is reduced below 6 $\mathrm{K}$. Because of the small gap energy of several Kelvins, we expect strong effects of magnetic field and pressure on the gapped state. The strength of hybridization in this compound can be controlled by substituting $\mathrm{Co}, \mathrm{Cu}$ and $\mathrm{Pt}$ for $\mathrm{Ni}$ in the nonmagnetic sublattice. The substituted samples serve as systems where one can examine the coherence effect on the gap formation. Furthermore, we compare the physical properties of CeNiSn with those of the 
isostructural compound $\mathrm{CePtSn}$, the latter of which is an antiferromagnetic Kondo compound with $\mathrm{T}_{\mathrm{N}}=7.5 \mathrm{~K} \cdot 18,19$

\section{SAMPLE PREPARATION AND CHARACTERIZATION}

Polycrystalline samples were prepared from stoichiometric starting materials by arcmelting in a purified argon atmosphere. The samples were homogenized by annealing in quartz ampoules for 10 days at $1000^{\circ} \mathrm{C}$. Single crystals were grown from Ames Laboratory Ce by a Czochralski technique in a triarc furnace or by a floating-zone method in an infrared mirror furnace. From metallographic examination and electron-probe microanalysis (EPMA) of the as-grown crystal, impurity phases of $\mathrm{CeNi}_{2} \mathrm{Sn}_{2}$ and cerium oxides were detected at the tail end and on the surface. As shown in Fig. 1, a line-shaped impurity phase of $\mathrm{Ce}_{3} \mathrm{Ni}_{4} \mathrm{Sn}_{3}$ of $1 \sim 10 \mu \mathrm{m}$ width was detected even in the central part of the crystal. The volume fraction of this phase is less than about $1 \%$ of the sample, which is much smaller than that assumed by Kasuya ${ }^{20}$ to explain the anomalous properties of CeNiSn based on a two-phase model. The impurity phase of $\mathrm{Ce}_{3} \mathrm{Ni}_{4} \mathrm{Sn}_{3}$ could not be eliminated by starting with off-stoichiometric compositions of $\mathrm{Ce}_{1.05} \mathrm{NiSn}_{1.03}$ and $\mathrm{Ce}_{1.07} \mathrm{NiSn}_{1.05}$. However, any deviation from the 1-1-1 stoichiomerty larger than the resolution of about 0.3 at. \%. was not detected by EPMA for the host phase in spite of the off-stoichiometric starting compositions.

The unit cell of CeNiSn consists of four formula units and hence contains an even number of valence electrons irrespective of the valence states of the $\mathrm{Ce}$ ions. We note here that in $\mathrm{CeRhSb}$, which exhibits similar semiconducting behavior, the number of valence electrons is supposed to be same as in CeNiSn. In the orthorhombic structures of the two compounds, the $\mathrm{Ce}$ atoms form a zigzag chain along the a axis. Recently, band structure calculations on CeNiSn have been performed by Yanase and Harima 21 using a selfconsistent LAPW method. According to their calculations, CeNiSn is a semimetal with a hole Fermi surface on the $\Delta$ axis and two electron Fermi surface centered at the $X$ points. The overlap of the valence band with the conduction band is about $600 \mathrm{~K}$. Since the $4 \mathrm{f}$ components are about $80 \%$ both at the top of the valence band and the bottom of the conduction band, we expect large effect of strong correlation among $4 \mathrm{f}$ electrons on the transport and magnetic properties of this compound.

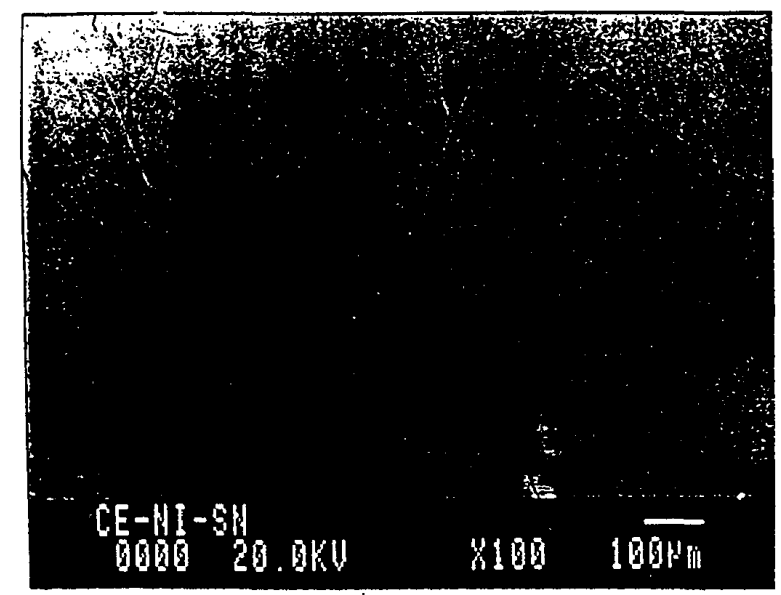

Fig. 1. Scanning electron micrograph of a $\mathrm{CcNiSn}$ crystal showing the impurity phase of $\mathrm{Ce}_{3} \mathrm{Ni}_{4} \mathrm{Sn}_{3}$. 


\section{BASIC PROPERTIES OF CeNiSn}

\subsection{Magnetic Susceptibility}

In Fig. 2, magnetic susceptibility $\chi(T)$ of a single crystalline sample of CeNiSn along the three principal axes is compared with that of CePtSn along the $a$ axis labelled as $\chi_{a}(T) .13,19$ We note here that the relationship $\chi_{a}>\chi_{b}>\chi_{c}$ at low temperatures is the same for the two compounds. Hence, we may attribute the magnetic anisotropy in CeNiSn to the effect of the hybridization similar to that in $\mathrm{CePtSn}$ where $\mathrm{Ce}$ ions are almost trivalent. However, the temperature dependence is weaker in CeNiSn at low temperatures below $100 \mathrm{~K}$, which is an indication of valence fluctuation in this compound. The VF character has been confurmed by inelastic neutron scattering experiments, ${ }^{22}$ by which no well-defined crystal-field (CF) excitations are observed. The maximum in $\chi_{\mathrm{a}}(\mathrm{T})$ at $12 \mathrm{~K}$ for CeNiSn is not associated with a long-range magnetic order as will be discussed later. Instead, it can be attributed to the development of antiferromagnetic correlations among quasiparticles as observed in neutron scattering experiments. ${ }^{23}$

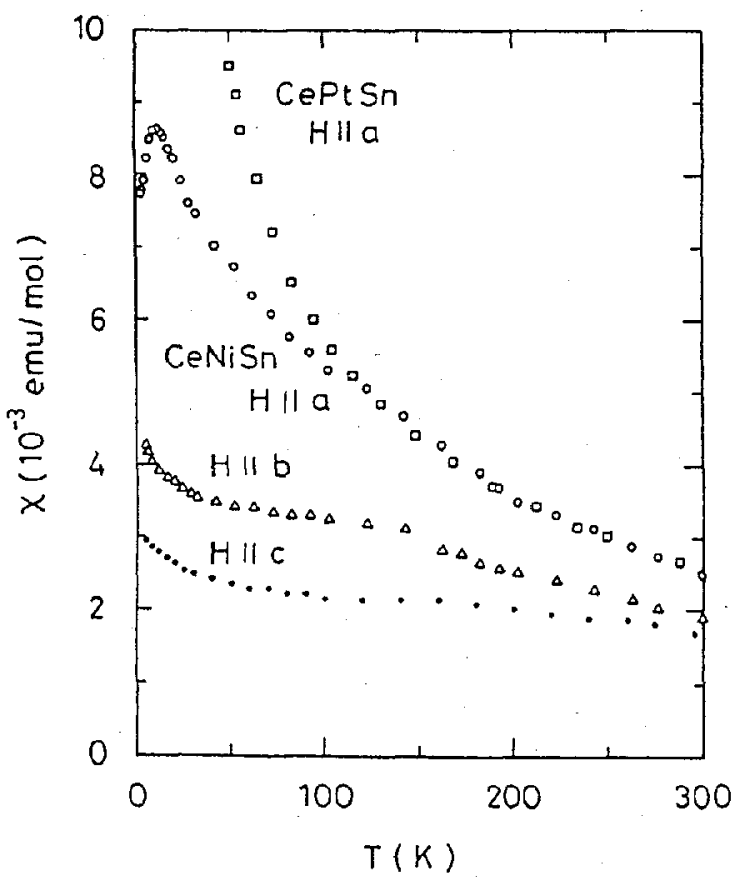

Fig. 2. Magnetic susceptibility vs temperature for single-crystalline CeNiSn $(\mathrm{H} / / \mathrm{a}, \mathrm{H} / / b, \mathrm{H} / / \mathrm{c})$ and CePiSn $(\mathrm{H} / / \mathrm{a})$.

\subsection{Electrical Resistivity}

Figure 3 represents the resistivity $p(T)$ of CeNiSn and CePtSn as a function of temperature. ${ }^{13,19}$ As temperature is decreased from $300 \mathrm{~K}$, the $\rho(\mathrm{T})$ curves of CeNiSn initially show a quasi-logarithmic increase in all directions, whereas those of CePtSn are metallic. From a local maximum around $100 \mathrm{~K}$ for $\rho_{\mathrm{a}}(\mathrm{T})$ and $60 \mathrm{~K}$ for $\mathrm{pb}_{\mathrm{b}}(\mathrm{T})$, the Kondo temperature $\mathrm{T}_{\mathrm{K}}$ of CeNiSn is estimated to be about $100 \mathrm{~K}$ for the degenerate $\mathrm{J}=5 / 2$ manifold. Another $\ln \mathrm{T}$ dependence for $\rho_{\mathrm{a}}(\mathrm{T})$ appears between 15 and $40 \mathrm{~K}$, which is similar to that 


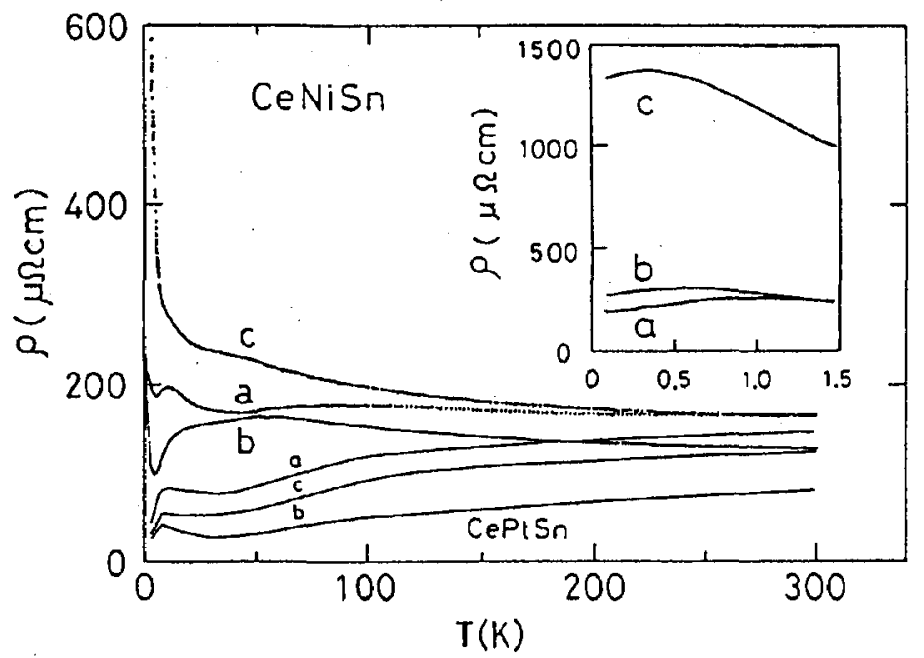

Fig. 3. Electrical resistivity vs tempcrature for single-crystalline CeNiSn and CePtSn.

found in the magnetic part of the resistivity in $\mathrm{CePtSn} .{ }^{19}$ The close similarity suggests the presence of another Kondo scale of about $30 \mathrm{~K}$ for the $\mathrm{CF}$ ground state in CeNiSn although the $C F$ level scheme is not well defined.

A local maximum in $\rho_{a}(T)$ appears at the same temperature of $12 \mathrm{~K}$ at which $\chi_{a}(T)$ shows the peak. The decrease in both $\rho_{a}(T)$ and $\rho_{b}(T)$ below $12 \mathrm{~K}$ indicates that the system goes into the coherent scattering regime. With further decrease of temperature below $6 \mathrm{~K}$, the resistivities turn to increase. An activation-type variation appears only in a small temperature range between 2.5 and $4.6 \mathrm{~K}$. Nevertheless, the gap energy $E_{g} / k_{B}=T_{g}$ in the formula $\rho(T)$ $=\rho_{\mathrm{o}} \exp \left(\mathrm{E}_{\mathrm{g}} / 2 \mathrm{k}_{\mathrm{B}} \mathrm{T}\right)$ was deduced as $1.0,4.8$ and $8.0 \mathrm{~K}$ for the $a, b$ and $c$ axes, respectively. Such a large difference in $T_{g}$ implies an anisotropic gapping of the density of states on the Fermi surface. The value of $T_{g}$ along the $c$ axis is still one order of magnitude smaller than that reported for $\mathrm{Ce}_{3} \mathrm{Pt}_{3} \mathrm{Bi}_{4}$. As shown in the inset of Fig. 3, $\rho_{c}(\mathrm{~T})$ and $\rho_{b}(\mathrm{~T})$ pass through a weak maximum at 0.4 and $0.6 \mathrm{~K}$, respectively, and decrease with further decreasing temperature. A plausible explanation for this temperature dependence is that the gapping of the quasiparticle band is incomplete or there exist impurity bands in the gap.

\subsection{Hall Effect}

The temperature dependence of the Hall coefficient $\mathrm{R}_{\mathrm{H}}$ for three configurations $\mathrm{H} / / \mathrm{a}$ $(\mathrm{I} / / b), \mathrm{H} / / b(\mathrm{I} / / c)$ and $\mathrm{H} / / c(\mathrm{I} / / b)$ is represented in Fig. 4 from Ref. 15. The three curves rise rapidly with decreasing temperature below $100 \mathrm{~K}$ and exhibit a positive peak around $9 \mathrm{~K}$, followed by a precipitous drop to a negative value. The positive $R_{H}$ peak of the size of $5 \times 10^{-3} \mathrm{~cm}^{3} / \mathrm{C}$ is in common with those found in heavy-fermion compounds like $\mathrm{CeAl}_{3}$ and $\mathrm{CeRu}_{2} \mathrm{Si}_{2} .{ }^{24}$ Acording to the theory of Fert and Levy, 25 the strong temperature dependence of $R_{H}$ with a positive peak arises from the contribution of the intrinsic skew scattering. Further, the extraordinary part of $\mathrm{R}_{\mathrm{H}}$ is proportional to the product of $\chi(\mathrm{T})$ and magnetic resistivity $\rho_{m}(T)$. Between 100 and $10 \mathrm{~K}, \mathrm{R}_{\mathrm{H}}(\mathrm{H} / / \mathrm{a})$ approximately follows the product. Since the peak temperature of $R_{H}$ in heavy-fermion systems is regarded as the 


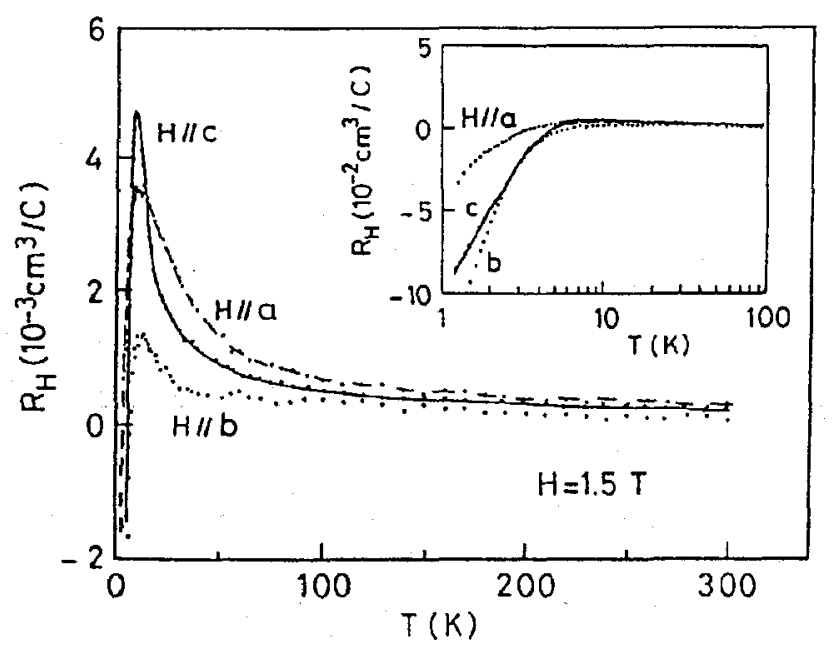

Fig. 4. Hall coefficient of CeNiSn as a function of temperature taken for three configuration; H//a (I//b), $\mathrm{H} / / b(\mathrm{I} / / \mathrm{c})$ and $\mathrm{H} / / c(\mathrm{I} / / b)$ (after ref, 15).

onset of coherence, ${ }^{24}$ the above result indicates that the electronic state in CeNiSn gradually goes into a coherent scattering regime below $9 \mathrm{~K}$. This temperature is somewhat lower than the maximal temperature in $\chi_{\mathrm{a}}(\mathrm{T})$ and $\rho_{\mathrm{a}}(\mathrm{T})$ at $12 \mathrm{~K}$. The strong decrease in $\mathrm{R}_{\mathrm{H}}$ below $5 \mathrm{~K}$ can be ascribed to the reduction of carrier density caused by the opening of the energy gap in the density of states. If we assume a single type of carriers, the concentration at $1.3 \mathrm{~K}$ is estimated to be $4.6 \times 10^{-3}$ per formula unit from the data for $\mathrm{H} / / \mathrm{c}$.

\subsection{Specific Heat}

The specific heat $\mathrm{C}$ of a single crystalline sample of $\mathrm{CeNiSn}$ is shown in Fig. 5 in a plot of $\mathrm{C} / \mathrm{T}$ vs $\mathrm{T}^{2}$ for $\mathrm{T}<16 \mathrm{~K}$. No appreciable anomaly exists near $12 \mathrm{~K}$, and hence the peaking in both $\chi_{a}(T)$ and $\rho_{a}(T)$ at $12 \mathrm{~K}$ does not originate from a long-range magnetic order. The value of $\mathrm{C} / \mathrm{T}$ decreases almost linearly with $\mathrm{T}^{2}$ down to nearly $6 \mathrm{~K}$ and then suddenly diminishes. This temperature dependence is consistent with the opening of a gap below $6 \mathrm{~K}$ as inferred from the transport properties. Furthermore, the large value of $\mathrm{C} / \mathrm{T}$ of $0.2 \mathrm{~J} / \mathrm{K}^{2}$ mol near $6 \mathrm{~K}$ indicates the development of a narrow band of heavy quasiparticles antecedent to the gap opening. Using the relation between $\gamma$ and $\mathrm{T}_{\mathrm{K}}$ derived for a single Kondo impurity, $\mathrm{T}_{\mathrm{K}}=0.68 \mathrm{R} / \gamma$ ( $\mathrm{R}$ is the gas constant), ${ }^{26} \mathrm{~T}_{\mathrm{K}}$ is estimated as $28 \mathrm{~K}$. This temperature is within the lower temperature range where $\rho_{a}(T)$ increases as $\ln T$, and thus this $T_{K}$ can be regarded as the Kondo temperature for the $C F$ ground state.

The magnetic contribution to the specific heat, $C_{m}$, was estimated by subtracting the data of LaNiSn from that of CeNiSn. As shown in the inset of Fig. $5, \mathrm{C}_{\mathrm{m}} / \mathrm{T}$ reveals a pronounced maximum near $6.7 \mathrm{~K}$. The magnetic entropy up to $20 \mathrm{~K}$ amounts to only half of RIn2. Between 1.5 and $5 \mathrm{~K}, \mathrm{C}_{\mathrm{m}} / \mathrm{T}$ shows a linear variation, $\mathrm{C}_{\mathrm{m}} / \mathrm{T}=\gamma+\mathrm{AT}$, as opposed to the $T^{2}$ dependence of $C_{m} / T$ in usual metallic systems. The observed temperature dependence is consistent with the renormalized density of states with a V-shaped gap near the Fermi level $E_{F}$, which was first proposed based on the results of NMR experiments. 27 The nuclear-spin lattice relaxation rate $1 / \mathrm{T}_{1}$ of ${ }^{119} \mathrm{Sn}$ in $\mathrm{CeNiSn}$ was found to be proportional to $\mathrm{T}^{3}$ between 0.4 and $1.3 \mathrm{~K}$. The proposed density of states is proportional to $\left|\mathrm{E}-\mathrm{E}_{\mathrm{F}}\right| / \mathrm{E}_{\mathrm{g}}$, which yields a $T^{3}$ dependence for $1 / T_{1}$ and a $T^{2}$ dependence for $C_{m}$ at low temperatures below $\mathrm{T}_{\mathrm{g}}=\mathrm{E}_{\mathrm{g}} / \mathrm{k}_{\mathrm{B}}$. 


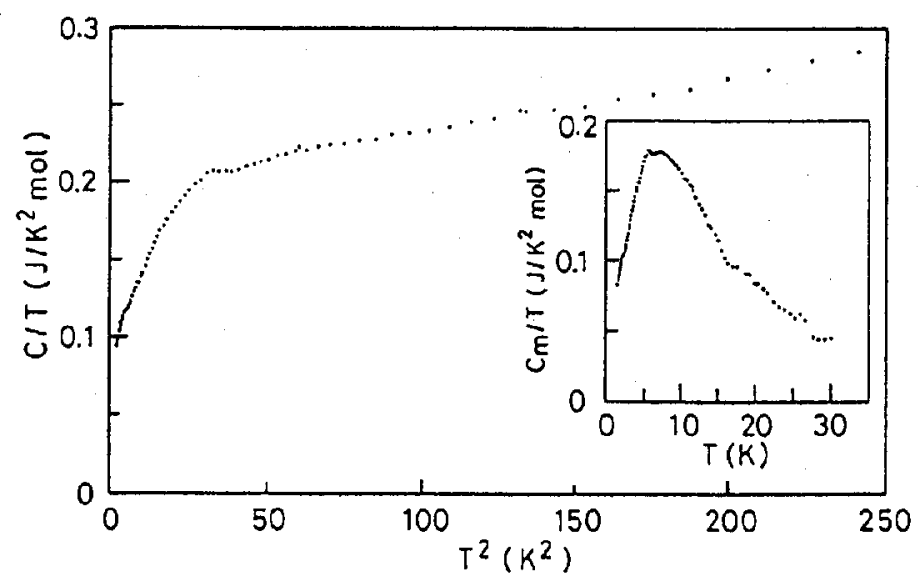

Fig. 5. Specific heat divided by temperature $\mathrm{C} / \mathrm{T}$ vs $\mathrm{T}^{2}$ for $\mathrm{CeNiSn}$. The inset shows the magnetic contribution to the specific heat divided by temperature $C_{m} / T$ vs $T$.

\subsection{Magnetic Correlations Sudied by NMR and $\mu \mathrm{SR}$}

Both NMR and $\mu$ SR techniques have been employed to study the magnetic correlations in CeNiSn at low temperatures. Kyogaku et al. ${ }^{28}$ extended the temperature range of NMR experiments down to $80 \mathrm{mK}$. They observed a strong deviation of $1 / \mathrm{T}_{1}$ of ${ }^{119} \mathrm{Sn}$ from the $\mathrm{T}^{3}$ behavior below $0.4 \mathrm{~K}$. With further decrease of temperature below $0.13 \mathrm{~K}, 1 / \mathrm{T}_{1}$ decreases exponentially together with an increase in the line width. The results suggest that the pseudogap state becomes unstable below $0.4 \mathrm{~K}$ and a spin excitation gap is induced by the development of quasistatic magnetic correlations.

Krazer et al. ${ }^{29}$ revealed from $\mu$ SR experiments that CeNiSn exhibits properties typical of a paramagnet moving towards magnetic order below $1 \mathrm{~K}$. However, no transition into long-range order was observed down to $33 \mathrm{mK}$. The formation of extended spin correlation up to short-range order is deduced from the unusual dependence of muon spin relaxation rate and muon spin precession frequency on external field.

\section{HIGH-MAGNETIC FIELD STUDIES}

\subsection{Magnetization}

The field dependence of magnetization $\mathrm{M}(\mathrm{H})$ of single crystal CeNiSn at $1.3 \mathrm{~K}$ is represented in Fig. 6 from Ref. 16. The $\mathrm{M}(\mathrm{H})$ curve only along the $a$ axis exhibits a weak metamagnetic-like transition near $13 \mathrm{~T}$. It is more clearly seen in the derivative susceptibility $\mathrm{dM} / \mathrm{dH}$ vs $\mathrm{H}$. However, the increase in $\mathrm{M}$ associated with the transition is much smaller than that found in nonmagnetic heavy-fermion compounds like CeRu2 $\mathrm{Si}_{2} .{ }^{30}$ This fact suggests that the weak transition in CeNiSn is not due to the suppression of antiferromagnetic intersite interactions as found in $\mathrm{CeRu}_{2} \mathrm{Si}_{2}$ but due to the collapse of the pseudogap. Above $20 \mathrm{~T}, \mathrm{M}_{\mathrm{a}}(\mathrm{H})$ increases linearly with increasing field and attains 0.3 $\mu_{\mathrm{B}} / \mathrm{Ce}$ at $36 \mathrm{~T}$. The size of the magnetization is only one fourth of that found in the isostructural, antiferromagnetic compound CePtSn, $1.2 \mu_{\mathrm{B}} / \mathrm{Ce}{ }^{19}$ The small and linearly increasing moment in CeNiSn can be interpreted as a result of strong Kondo-type interaction persisting even after the pseudogap has collapsed. Assuming the effective moment of 0.3 


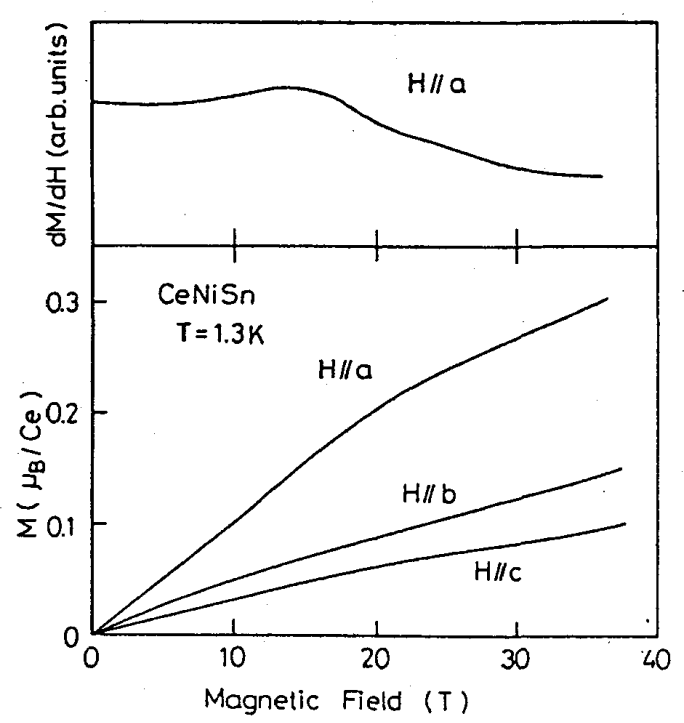

Fig. 6. Magnetization of CeNiSn along the three principal axes at $1.3 \mathrm{~K}$ (after ref. 16).

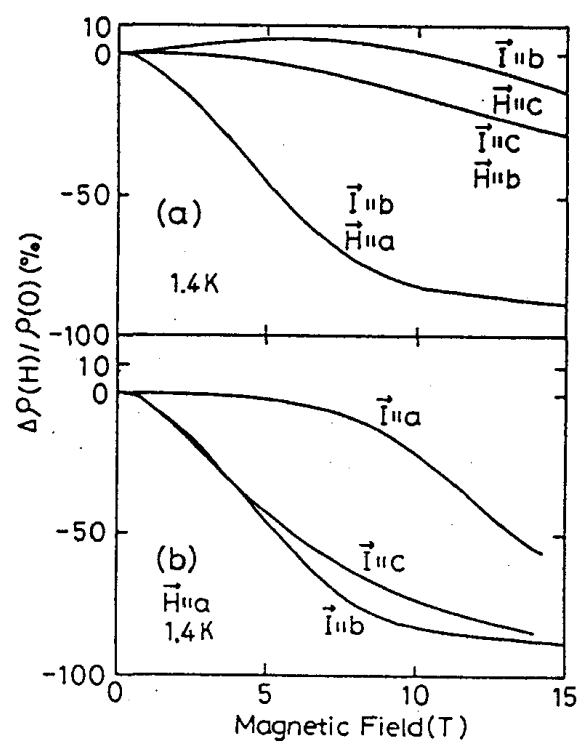

Fig. 7. Magnetoresistance of CeNiSn at $1.4 \mathrm{~K}$ (after ref. 14).

$\mu_{\mathrm{B}} / \mathrm{Ce}$, the magnetic energy at the transition field of $13 \mathrm{~T}$ corresponds to the thermal energy of $2.6 \mathrm{~K}$, which is comparable to the gap energy estimated from the $a$-axis resistivity.

\subsection{Magnetoresistance}

Strong suppression of the energy gap in CeNiSn by application of magnetic field was first demonstrated by the magnetoresistance measurements on a polycrystalline sample. ${ }^{12}$ The resistivity at $1.7 \mathrm{~K}$ was found to decrease from 730 to $200 \mu \Omega \mathrm{cm}$ as the field is raised to $24 \mathrm{~T}$. The results obtained on single crystalline samples show very strong anisotropy. 14 The normalized magnetoresistance $\Delta \rho(\mathrm{H}) / \rho(0)$, where $\Delta \rho(\mathrm{H})=\rho(\mathrm{H})-\rho(0)$, at $1.4 \mathrm{~K}$ are presented in Figs. $7(\mathrm{a})$ and $7(\mathrm{~b})$. At $\mathrm{H}=15 \mathrm{~T}$, the negative magnetoresistance for $\mathrm{H} / / \mathrm{a}$ attains $-88 \%$, which is much larger than for $\mathrm{H} / / b$ and $\mathrm{H} / / c$. Thus, the energy gap is most sensitive to the magnetic field applied along the easy $a$ axis. For $\mathrm{H} / / \mathrm{a}$, the dependence of magnetoresistance on the current direction was further examined. In Fig. 7(b), the field dependence of $\Delta \rho(H) / \rho(0)$ for $I / / c$ is similar to that for $I / / b$, whereas $\Delta \rho(H) / \rho(0)$ for $I / / a$ is almost constant up to $4 \mathrm{~T}$ and then gradually decreases with increasing freld. These results suggest a strong anisotropic scattering mechanism under magnetic fields.

Shown in Fig. 8 is the temperature dependence of the resistivity along the three principal axes in fields of 0,12 and $14 \mathrm{~T}$. At $\mathrm{H}=0 \mathrm{~T}, \rho_{\mathrm{a}}(\mathrm{T})$ exhibits a maximum near $11.4 \mathrm{~K}$, which has been ascribed to the development of antiferromagnetic correlations. In a field of $14 \mathrm{~T}$ parallel to the $a$ axis, this maximum is almost smeared out. The strong suppression of the upturn below $6 \mathrm{~K}$ is a result of the gap suppression by magnetic fields. A drastic effect occurs in the resistivity for the configuration $\mathrm{I} / \mathrm{b}$ and $\mathrm{H} / / \mathrm{a}$, which indicates metallic behavior and is in contrast to the semiconductor-like behavior for $\mathrm{H} / / c$. Furthermore, at temperatures below $4 \mathrm{~K}$, it obeys a $\mathrm{T}^{2}$ dependence with a coefficient of $1.0 \mu \Omega \mathrm{cm} / \mathrm{K}^{2}$ and a residual resistivity of $39 \mu \Omega \mathrm{cm}$. The size of this coefficient is typical for moderately heavy fermion systems. 


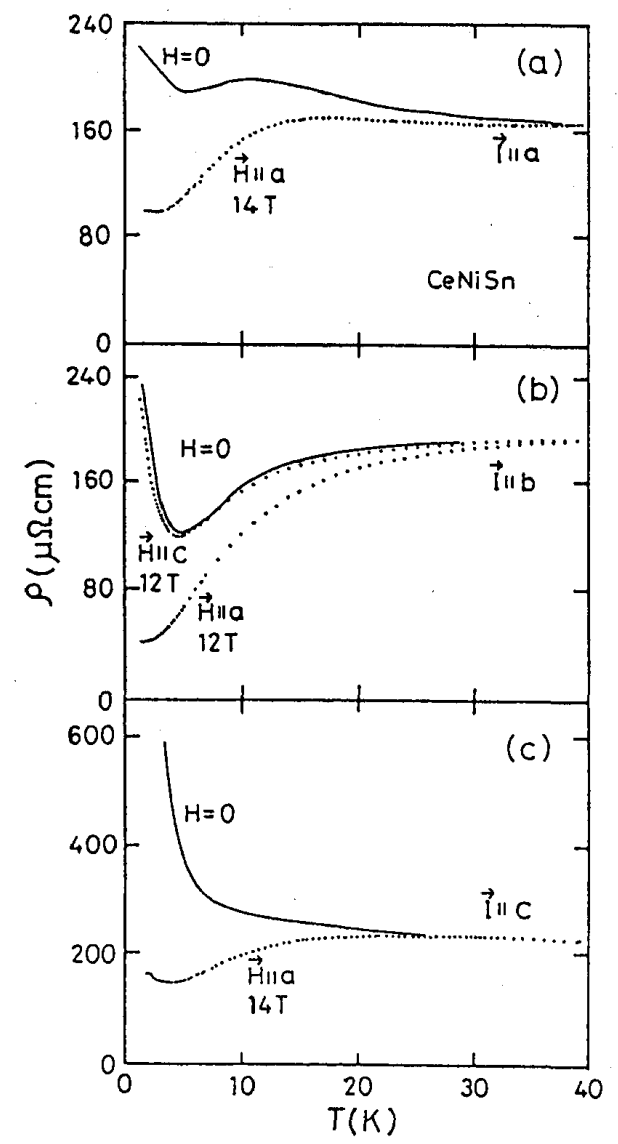

Fig. 8. Electrical resistivity vs temperature for CeNiSn in external fields 0,12 and $14 \mathrm{~T}$ for electrical currents along the three principal axes (after ref. 14).

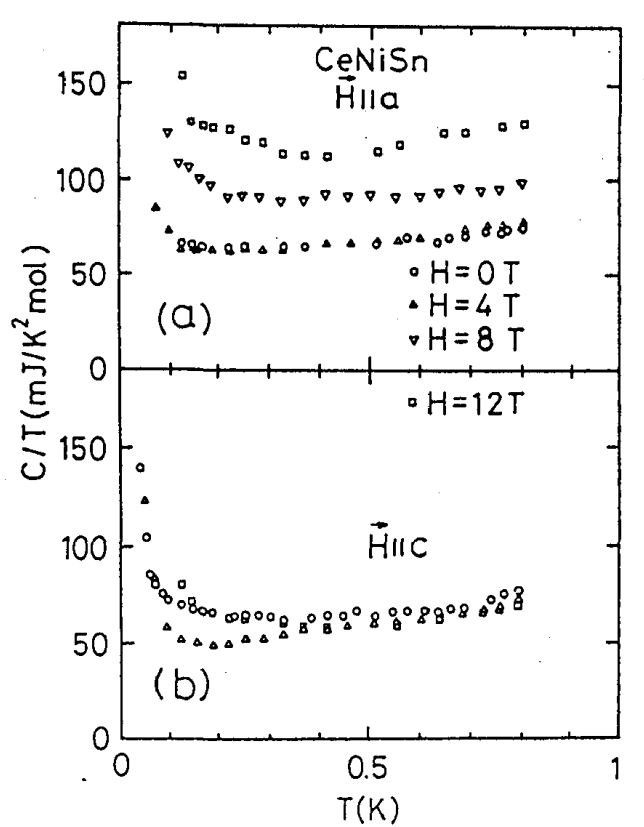

Fig. 9. Specific heat of CeNiSn plotted as $\mathrm{C} / \mathrm{T}$ vs $\mathrm{T}$ in magnetic fields for (a) $\mathrm{H} / / \mathrm{a}$ and (b) $\mathrm{H} / / \mathrm{c}$ (after ref. 14).

\subsection{Specific Heat in Magnetic Fields}

The suppression of the energy gap by magnetic field was further studied by specific-heat measurements. ${ }^{14}$ Temperature variations of the specific heat of CeNiSn in magnetic fields parallel to the $a$ and $c$ axes are shown in Figs. 9(a) and 9(b), respectively. At $\mathrm{H}=0 \mathrm{~T}, \mathrm{C} / \mathrm{T}$ is almost proportional to $\mathrm{T}$ between 0.3 and $0.8 \mathrm{~K}$ and the linear extrapolation to $\mathrm{T}=0 \mathrm{~K}$ yields a $\gamma$ value of $57 \mathrm{~mJ} / \mathrm{K}^{2} \mathrm{~mol}$. This size of $\gamma$ value seems to be too large to be ascribed to the contribution from impurity phases. Rather, it may be the contribution from the residual density of states at $\mathrm{E}_{\mathrm{F}}$ in the pseudogap, as inferred from the saturation of the resistivity below $1 \mathrm{~K}$. The origin of the upturn in $\mathrm{C} / \mathrm{T}$ below $0.2 \mathrm{~K}$ is not clear yet.

When magnetic field is raised to $12 \mathrm{~T}$, the value of $\mathrm{C} / \mathrm{T}$ is strongly enhanced for $\mathrm{H} / / a$, whereas it is almost unchanged for $\mathrm{H} / / \mathrm{c}$. For $\mathrm{H} / / a$, the field dependence of $\mathrm{C} / \mathrm{T}$ was measured at $0.15,0.42$ and $0.76 \mathrm{~K} .{ }^{14}$ The values of $\mathrm{C} / \mathrm{T}$ at these temperatures stay constant for $\mathrm{H}<4 \mathrm{~T}$ and then increase monotonically from about 70 to $125 \mathrm{~mJ} / \mathrm{K}^{2} \mathrm{~mol}$. This large enhancement is consistent with the heavy-fermion behavior in $\rho_{b}(T)$ at $12 \mathrm{~T}$ in Fig. 8(b). These results support the idea that the density of states in the minimum of the V-shaped pseudogap is increased by application of magnetic field along the easy axis of 
magnetization. In this anisotropic suppression of the pseudogap, a strong spin polarization of the renormalized band should play an important role.

\section{HIGH-PRESSURE STUDIES}

The effect of application of pressure on the gapped state in CeNiSn has been studied by Kurisu et al. 31,32 from resistivity measurements. As a typical result, the $a$-axis resistivity is shown in Fig. 10. With increasing pressure, the upturn in $\rho_{a}(T)$ below $6 \mathrm{~K}$ is strongly suppressed, and the local maximum at $12 \mathrm{~K}$ shifts to higher temperatures. Above $12 \mathrm{kbar}$, the resistivity shows metallic behavior with a single maximum around $100 \mathrm{~K}$. This maximum, which originates in the interplay of the Kondo effect and the CF effect, shifts also to higher temperatures. Generally, application of pressure on cerium-based Kondolattice compounds increases the degree of the 4f-ligand hybridization so that the renormalized band broadens. ${ }^{33}$ As a result, the value of $T_{K}$ is increased and hence the maximal temperature of the resistivity due to the Kondo effect is elevated. In fact, we find large shift of both the peaks in $\rho_{\mathrm{a}}(\mathrm{T})$, which are originally at 12 and $65 \mathrm{~K}$, respectively, to 30 and $180 \mathrm{~K}$. The broadening of the renormalized band should also be responsible for the suppression of the gap at low temperatures. In other words, the gap formation in CeNiSn is

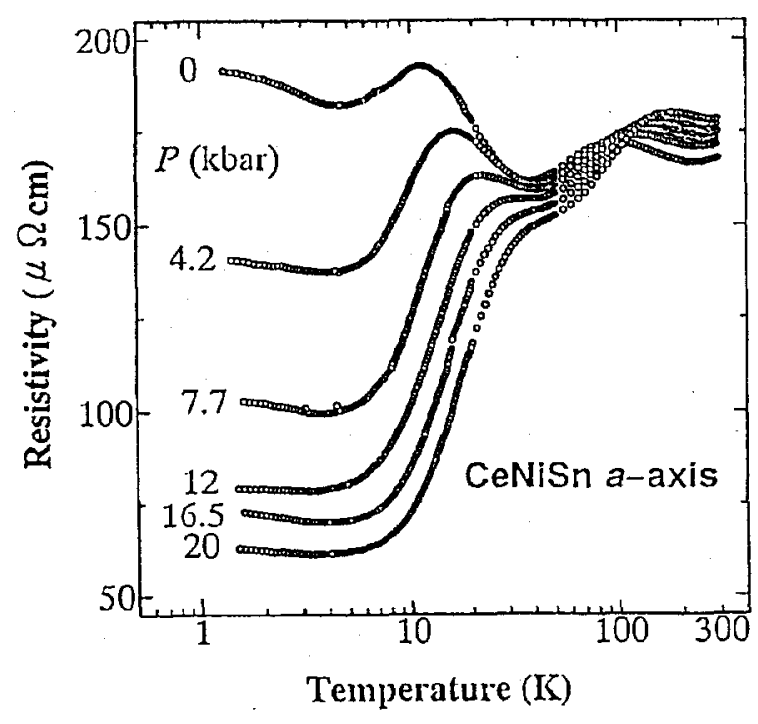

Fig. 10. Electrical resistivity vs $\ln T$ for singlecrystalline CeNiSn along the $a$ axis under various applied hydrostatic pressures.

Fig. 11. Electrical resistivity vs temperature for CeNiSn at hydrostatic pressures 0,18 and $20 \mathrm{kbar}$.

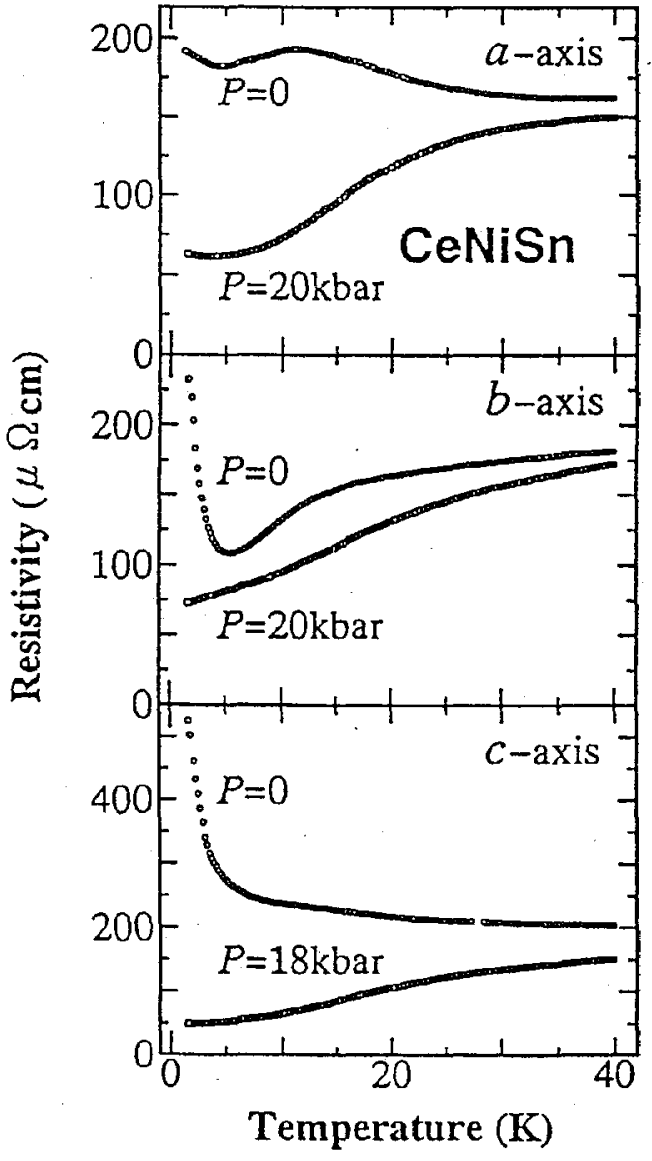


strongly suppressed by the increase of the degree of hybridization. We will see in the next section that the reduced hybridization by negative chemical pressure also suppresses the gap.

It is interesting to compare the effect of pressure on the resistivity with that of magnetic field. Comparing the resistivity curves in Figs. 8 and 11, we notice that the effect of application of $20 \mathrm{kbar}$ is comparable with that of a magnetic field of $14 \mathrm{~T}$ applied along the $a$ axis. However, a simple scaling is rather difficult because the negative magnetoresistance is significant only below $30 \mathrm{~K}$, whereas the overall temperature dependence is changed by application of pressure.

\section{EFFECT OF ALLOYING}

Low-temperature properties of heavy-fermion compounds are generally very sensitive to a small amount of substitution. ${ }^{34} \mathrm{We}$ expect that the substitution of $3 \mathrm{~d}$ element $\mathrm{Co}$ or $\mathrm{Cu}$ for the $\mathrm{Ni}$ atom in $\mathrm{CeNiSn}$ would change the number of conduction electrons. If the $\mathrm{Ni}$ atom is replaced by the $4 \mathrm{~d}$ or $5 \mathrm{~d}$ atom in the same column in the periodic table, i.e., $\mathrm{Pd}$ or $\mathrm{Pt}$, then the unit cell volume would increase without changing the number of conduction electrons so much. Keeping this in mind, we have performed systematic studies of the substituted systems $\mathrm{CeNi}_{1-\mathrm{x}} \mathrm{T}_{\mathrm{x}} \mathrm{Sn}$ with $\mathrm{T}=\mathrm{Co}, \mathrm{Cu}$ and $\mathrm{Pt}$.

Figure 12 shows variations of the lattice parameters with $\mathrm{x}$. The substitution of $\mathrm{Co}$ for $\mathrm{Ni}$ hardly changes the lattice parameters, whereas that of $\mathrm{Cu}$ leads to a linear increase in the three parameters. By the substitution of $\mathrm{Pt}$, the $c$ parameter increases significantly but the $a$ parameter slightly decreases. For $\mathrm{CeNi}_{1-x} \mathrm{Cu}_{\mathrm{x}} \mathrm{Sn}$, we previously reported that the energy gap disappears near $\mathrm{x}=0.1$ and then a long-range antiferromagnetic order develops for $\mathrm{x} \geq$ 0.13.12 Hereafter, we compare the magnetic and thermal properties of the Co and $\mathrm{Pt}$ substituted systems. Temperature dependences of the magnetic susceptibility $\chi(T)$ of

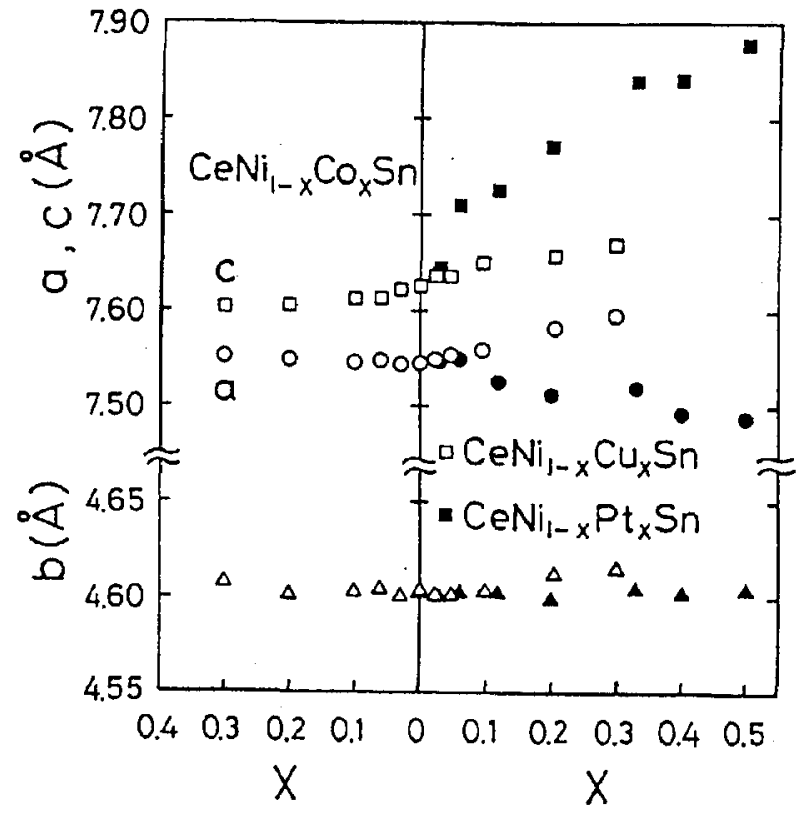

Fig. 12. Variations of lattice parameters of $\mathrm{CeNi}_{1-x} \mathrm{~T}_{X} \mathrm{Sn}(\mathrm{T}=\mathrm{Co}, \mathrm{Cu}$ and $\mathrm{Pt})$. 

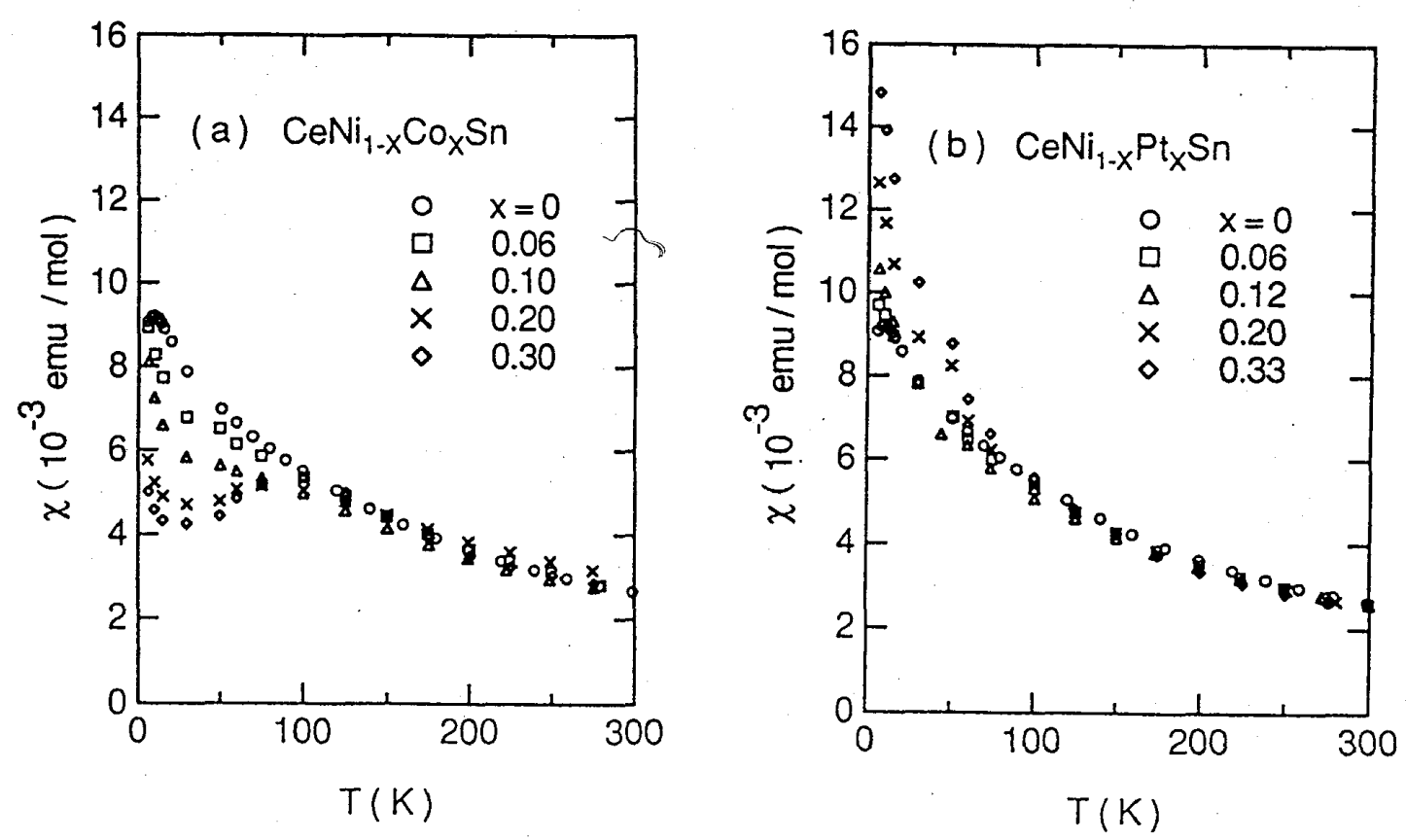

Fig. 13. Magnetic susceptibility vs temperature for field-aligned polycrystalline samples of (a) CeNil-xCoxSn and (b) CeNi1-xPtxSn.

polycrystalline samples of $\mathrm{CeNi}_{1-\mathrm{x}} \mathrm{T}_{\mathrm{X}} \mathrm{Sn}$ for $\mathrm{T}=\mathrm{Co}$ and $\mathrm{Pt}$ are shown in Figs. 13 (a) and 13(b), respectively. The measurements were performed on powdered samples which were pre-aligned by application of a magnetic field of $14 \mathrm{~T}$ at $4.2 \mathrm{~K}$.

The data of CeNiSn with a maximum around $12 \mathrm{~K}$ agree with those of $\chi(\mathrm{T})$ along the $a$ axis of the single crystalline sample as was shown in Fig. 2 . This agreement guarantees that the powders are aligned along the easy $a$ axis of the magnetization. In Fig. 13(a), the values of $\chi(\mathrm{T})$ for $\mathrm{T}<100 \mathrm{~K}$ decrease as $\mathrm{x}$ is increased in $\mathrm{CeNi}_{1-\mathrm{x}} \mathrm{Co}_{\mathrm{x}} \mathrm{Sn}$. At higher Co concentration $x \geq 0.2$, a broad maximum appears around $100 \mathrm{~K}$ and the value of the paramagnetic Curie temperature estimated from the Curie-Weiss fitting exceeds $-130 \mathrm{~K}$. These features are the signals for the transition to the VF regime. The Pt substitution has an opposite effect on the system and leads to the Kondo regime. In Fig. 13(b), the lowtemperature value of $\chi(T)$ increases with increasing $x$ in $\mathrm{CeNi}_{1-x} \mathrm{Pt}_{\mathrm{x}} \mathrm{Sn}$, resulting in the recovery of the Curie-Weiss behavior down to low temperatures. The paramagnetic Curie temperature remains constant at about $-70 \mathrm{~K}$.

The trend toward either the VF or the Kondo regime is confirmed by the result of magnetization measurements at $4.2 \mathrm{~K}$. As shown in Fig. 14(a), the slope of the magnetization curve decreases with increasing Co concentration. A downward curvature near $4 \mathrm{~T}$ for $x \geq 0.1$ may indicate the saturation of impurity contribution. All the magnetization curves of the $\mathrm{Pt}$ substituted samples are almost linear with field. The value of $\mathrm{M}(\mathrm{H})$ at $\mathrm{H}=14.6 \mathrm{~T}$ increases linearly with increasing $\mathrm{Pt}$ concentration, whereas it decreases with $\mathrm{Co}$ concentration at almost the same rate of $\mathrm{dM} / \mathrm{dx}=0.42 \mu_{\mathrm{B}}$.

As mentioned above, Co substitution for $\mathrm{Ni}$ in $\mathrm{CeNiSn}$ may decrease the number of conduction electrons. The Fermi level accordingly lowers toward the level of the unrenormalized $4 \mathrm{f}$ states, $\mathrm{E}_{\mathrm{f}}$. For a Cerium impurity in metal, the Kondo temperature $\mathrm{T}_{\mathrm{K}}$ is proportional to $\exp \left[-1 /|J| N\left(E_{F}\right)\right]$, where $J$ is the effective exchange integral given by 

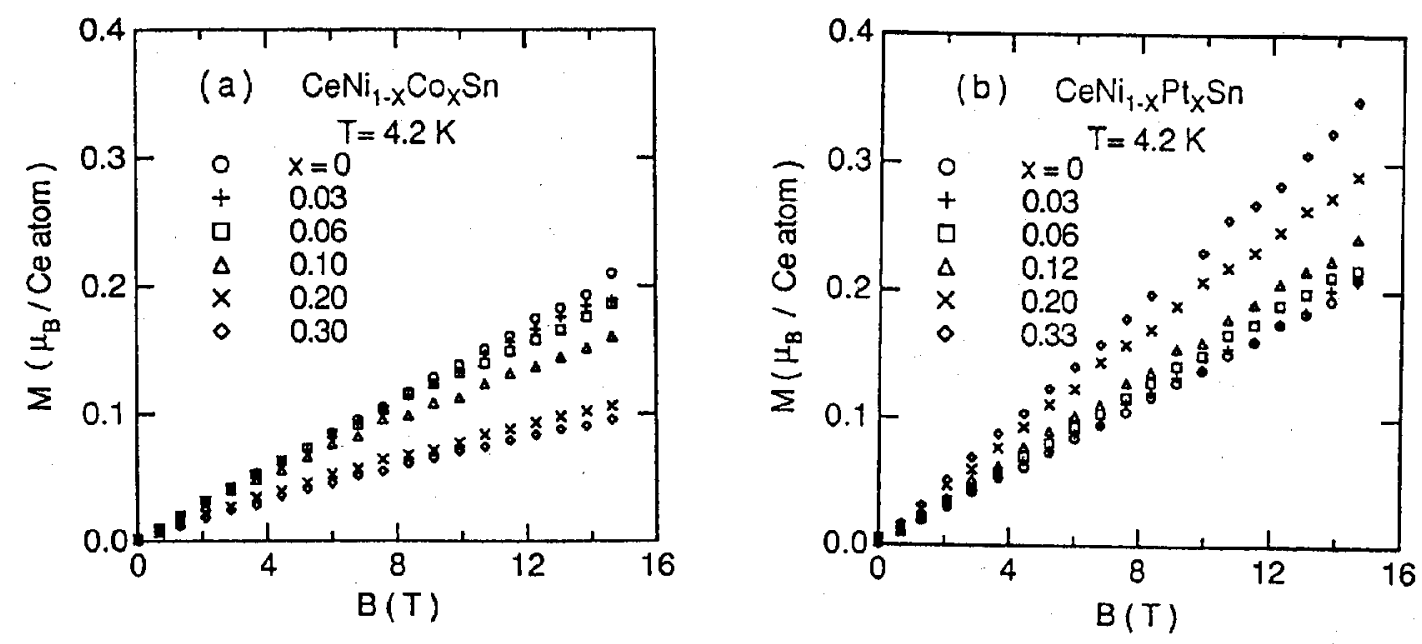

Fig. 14. Magnetization vs magnetic field for powdered polycrystalline samples of (a) $\mathrm{CeNi}_{1-x} \mathrm{Co}_{x} \mathrm{Sn}$ and (b) $\mathrm{CeNi}_{1-x} \mathrm{Pt}_{\mathbf{x}} \mathrm{Sn}$.

$J=\left|V_{k, f}\right|^{2} /\left(E_{f}-E_{F}\right)$ with the hybridization matrix element $V_{k, f}$ between the $4 f$ state and the conduction electrons. ${ }^{35}$ Then, $\mathrm{T}_{\mathrm{K}}$ is expected to be strongly enhanced by Co substitution and the system is converted to the VF regime, as is experimentally observed. On the contrary, the negative chemical pressure induced by the $\mathrm{Pt}$ substitution may weakens the hybridization of the $4 \mathrm{f}$ states with the $\mathrm{Sn}-5 \mathrm{p}$ and $\mathrm{Ni}-3 \mathrm{~d}$ states. In fact, recent photoemission study by Nohara et al. ${ }^{36}$ have revealed that the hybridization weakens significantly on going from CeNiSn to CePtSn. The decrease of $\mathrm{V}_{k, f}$ in the above expression for $\mathrm{T}_{\mathrm{K}}$ results in the lowering of the value of $T_{K}$. This is consistent with the transition into the Kondo regime observed for the $\mathrm{Pt}$ substituted system.

The effect of the substitution on the gapped state in CeNiSn was studied by the measurements of resistivity and specific heat. However, the temperature dependence of resistivity of polycrystalline samples of $\mathrm{CeNi}_{1-x} \mathrm{~T}_{x} \mathrm{Sn}(\mathrm{T}=\mathrm{Co}$ and $\mathrm{Pt}$ ) was found to be very sample-dependent even for a fixed value of $\mathrm{x}$. This is presumably caused by the preferred orientation of the sample, as is expected from the highly anisotropic behavior in the the resistivity of the single crystalline sample (see Fig. 3 ). This situation did not allow us to study how the gap energy changes as a function of $x$.

The low-temperature specific heat of $\mathrm{CeNi}_{1-x} \mathrm{~T}_{\mathrm{x}} \mathrm{Sn}(\mathrm{T}=\mathrm{Co}$ and $\mathrm{Pt})$ changes smoothly with $x$ as shown in Fig. 15.37,38 For pure $\mathrm{CeNiSn}$, the sudden decrease in $\mathrm{C} / \mathrm{T}$ below $6 \mathrm{~K}$ originates from the gap formation in the density of states. With increasing $\mathrm{Pt}$ concentration, the value of $C / T$ increases and an upturn in $C / T$ appears for $x \geq 0.12$. This change implies that the density of quasiparticle states grows within the gap and eventually a heavy fermion band is formed. The Kondo temperature for the $x=0.2$ sample is estimated to be $25 \mathrm{~K}$ from an analysis of $\mathrm{C} / \mathrm{T}$ using the isolated Kondo impurity model. ${ }^{38}$ The pronounced peak at 2.1 $\mathrm{K}$ for $\mathrm{x}=0.33$ indicates the development of a long-range magnetic order for higher $\mathrm{Pt}$ concentration. This trend is consistent with the increased magnetic moment with $\mathrm{Pt}$ concentration, as was shown in Fig.14. We recall here that the transition into an antiferromagnetically ordered state is induced by the $\mathrm{Cu}$ substitution at a smaller concent- 


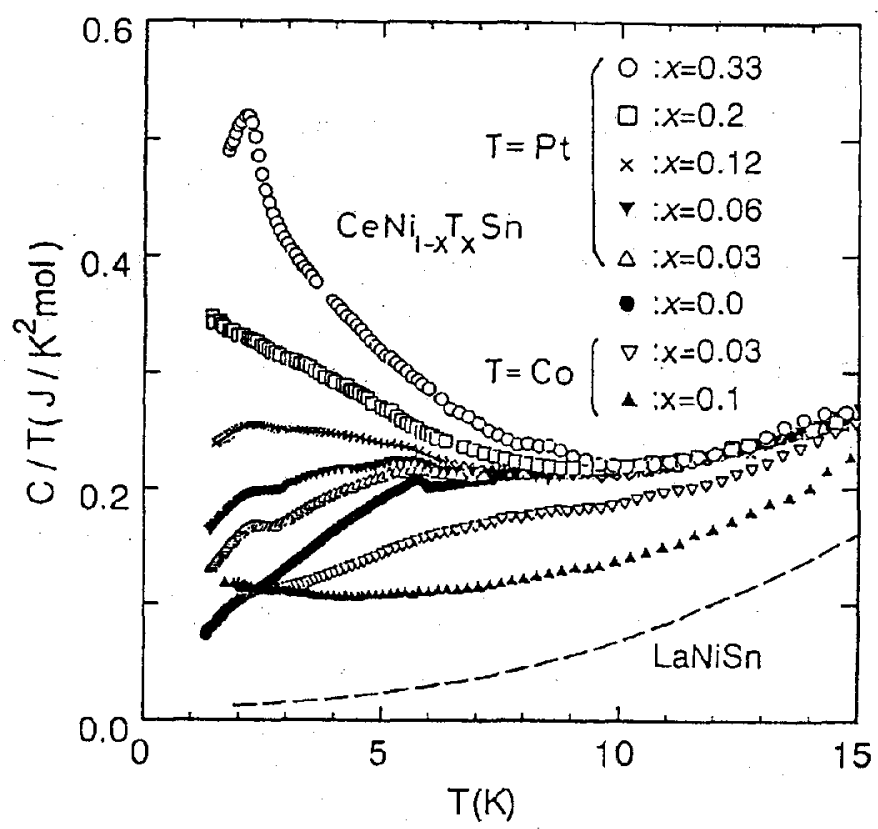

Fig. 15. Specific heat divided by temperature $\mathrm{C} / \mathrm{T}$ vs $\mathrm{T}$ for $\mathrm{CeNi} 1-\mathrm{x} \mathrm{T}_{\mathrm{X}} \mathrm{Sn}(\mathrm{T}=\mathrm{Co}$ and $\mathrm{Pt})$.

ration $x=0.13 .12$ In this case, the increase in both the number of $3 d$ electrons and the unitcell volume may promote the transition.

On the other hand, the substitution of only 3 at. $\%$ Co is enough to reduce the value of $\mathrm{C} / \mathrm{T}$ substantially throughout the temperature range below $30 \mathrm{~K}$. Thereby, the anomaly due to the gap formation below $6 \mathrm{~K}$ is also smeared out. This in turn suggests that a moderate mass-enhancement is a necessary condition for the gap formation. Comparing the results of the $\mathrm{Co}, \mathrm{Cu}$ and $\mathrm{Pt}$ substituted systems, we find that any replacement of about $10 \%$ of the $\mathrm{Ni}$ sublattice in CeNiSn closes the energy gap. This fact implies that the loss of the periodicity in the Kondo-lattice is very destructive for the gap formation.

\section{CONCLUDING REMARKS}

In this article, we reviewed our experimental attempts to understand the semiconductorlike behavior in CeNiSn at low temperatures. The results of transport, thermal and magnetic measurements characterize this compound as a rare example located near the crossover between the Kondo and VF regimes. The highly anisotropic behavior reflects the strong hybridization of the $4 f$ states with the $\mathrm{Sn}-5 \mathrm{p}$ and $\mathrm{Ni}-3 \mathrm{~d}$ states in the orthorhombic structure. The Kondo temperature of this system is about $28 \mathrm{~K}$. At low temperatures below $12 \mathrm{~K}$, coherence of local spin fluctuations develops, as indicated by the peaking in both $\rho_{a}(T)$ and $\chi_{\mathrm{a}}(\mathrm{T})$ at $12 \mathrm{~K}$ and in $\mathrm{R}_{\mathrm{H}}(\mathrm{T})$ at $9 \mathrm{~K}$. An anisotropic gap opens in the heavy-quasiparticle bands as temperature is reduced below $6 \mathrm{~K}$. This semiconducting state with a charge excitation gap of several Kelvins is destructible by applying either hydrostatic pressure of $20 \mathrm{kbar}$ or magnetic field of $13 \mathrm{~T}$ along the easy $a$ axis. Substitutions of $\mathrm{Co}$ and $\mathrm{Pt}$ for a few percent of $\mathrm{Ni}$ in CeNiSn destroy the energy gap and shift the system toward the VF and the heavy-fermion regimes, respectively. The combined results indicate that the gap formation in CeNiSn is very sensitive to the degree of hybridization of the $4 \mathrm{f}$ and the conduction electron states. It is also emphasized that the development of coherence in the Kondo lattice is crucial for the gap formation. 


\section{ACKNOWLEDGMENT}

The authors acknowledge fruitful collaborations with J. Sakurai, G. Kido, K. Sugiyama, M. Date, T. Hiraoka, M. Kyogaku, Y. Kitaoka, K. Asayama, D. Jaccard, U. Ahlheim, C. Geibel, F. Steglich, A. Krazer and G.M. Kalvius. We are benefited from valuable discussion with A. Yanase, S. Namatame, A. Fujimori, M. Kasaya, M. Kohgi, Y. Kuramoto and T. Kasuya. This work was supported in part by a Grant-in-Aid for Scientific Research and for International-Joint Research Program from Ministry of Education, Science and Culture of Japan.

\section{REFERENCES}

1. A. Menth, E. Buehler and T.H. Geballe, Phys. Rev. Lett. 22:295(1969).

2. A. Jayaraman, V. Narayanamurti, E. Bucher and R.G. Maincs, Phys. Rev. Lett. 25:1430(1970).

3. P. Haen, F. Holzberg, F. Lapierre, T. Penny and R. Tournier, in Valence Instabilities and Related Narrow Band Phenomena, ed. by R.D. Parks (Plenum, New York, 1977) p. 1495.

4. M. Kasaya, F. Iga, M. Takigawa and T. Kasuya, J. Magn. Magn. Mater. 47\&48:429(1985).

5. N.F. Mott, Phil. Mag. 30:403(1973).

6 T. Takabatake, Y. Nakazawa and M. Ishikawa, Jpn. J. Appl. Phys. Suppl. 26-3:547(1987).

7. I. Higashi, K. Kobayashi, T. Takabatake and M. Kasaya, to be published in J. Alloys Compds. (1992).

8. M.F. Hundley, P.C. Canficld, J.D. Thompson, Z. Fisk and J.M. Lawrence, Phys. Rev. B42:6842 (1990).

9. S.K. Malik and D.T. Adroja: Phys, Rev. B43:6277(1991).

10. P.S. Riseborough, Phys. Rev. B45:13984(1992).

11. P. Schlottmann, Phys. Rev. B46:998(1992).

12. T. Takabatake, Y. Nakazawa, M. Ishikawa, T. Sakakibara, K. Koga and I. Oguro, J. Magn. Magn. Mater. 76\&77:87(1988).

13. T. Takabatake, F. Teshima, H. Fujii, S. Nishigori, T. Suzuki, T. Fujita, Y. Yamaguchi, J. Sakurai and D. Jaccard, Phys. Rev. B41:9607(1990).

14. T. Takabatake, M. Nagasawa, H. Fujii, G. Kido, M. Nohara, S. Nishigori, T. Suzuki, T. Fujita, R. Helfrich, U. Ahlhcim, K. Fraas, C. Geibcl and F. Steglich, Phys. Rev. B45:5740(1992).

15. T. Takabatake, M. Nagasawa, H. Fujii, M. Nohara, T. Suzuki, T. Fujita, G. Kido and T. Hiraoka, J. Magn. Magn. Mater. 108:155(1992).

16. T. Takabatake, M. Nagasawa, H. Fujii, G. Kido, K. Sugiyama, K. Senda, K. Kido and M. Date, Physica B172:177(1992).

17. T. Takabatake and H. Fujii, to be published in Jpn. J. Appl. Phys. Ser.8 (1992).

18. J. Sakurai, Y. Yamaguchi, S. Nishigori, T. Suzuki and T. Fujita, J. Magn. Magn. Mater. 90\&91: 442(1990).

19. T. Takabatake, H. Iwasaki, G. Nakamoto, H. Fujii, H. Nakotte, F.R. de Boer and V. Sechovsky, to be published in Physica B 182(1992).

20 T. Kasuya, J. Phys. Soc. Jpn. 61:1863(1992).

21. A. Yanase and H. Harima, Progr. Theor. Phys. Jpn. Suppl. 108:19(1992).

22. M. Kohgi, K. Ohoyama, T. Osakabe and M. Kasaya, J. Magn. Magn. Mater. 108:187(1992).

23. T.E. Mason, G. Aeppli, A.P. Ramirez, K.N. Clausen, C. Broholm, N. Stücheli, E. Bucher and T.T.M. Palstra, Phys. Rev. Lett. 69:490(1992).

24. F. Lapierre, P. Haen, R. Brigs, A. Hamezić, A. Fert and J.P. Kappler, J. Magn. Magn. Mater. 63\&64: 338(1987).

25. A. Fert and P.M. Levy, Phys. Rev. B36:1907(1987). 
26. N. Andrei, K. Furuya and J.K. Loewenstein, Rev. Mod. Phys. 55:331(1983).

27. M. Kyogaku, Y. Kitaoka, H. Nakamura, K. Asayama, T. Takabatake, F. Teshima and H. Fujii, J. Phys. Soc. Jpn. 59:1728(1990).

28. M. Kyogaku, Y. Kitaoka, K. Asayama, T. Takabatake and H. Fujii, J. Phys. Soc. Jpn. 61:43(1992).

29. A. Kratzer, G.M. Kalvius, T. Takabatake, G. Nakamoto, H. Fujii and S.R. Kreitzman, Europhys. Lett. 19:649(1992).

30. J.M. Mignot, J. Flouquet, P. Haen, F. Lapierre, L. Puech and J. Voiron, J. Magn. Magn. Mater. 76\&77:97(1988).

31. M. Kurisu, T. Takabatake and H. Fujiwara, Solid State Commun. 68:595(1988).

32. M. Kurisu, T. Takabatake and H. Fujii, in this issue.

33. J.D. Thompson, J. Magn. Magn. Mater. 63\&64:358(1987).

34. N. Grewe and F. Steglich, in Handbook on the Physics and Chemistry of Rare Earths, ed. by K.A. Gschneidner, Jr, and L. Eyring (Elsevier, Amsterdam, 1991) Vol.14, p. 343.

35. B. Cornut and B. Coqblin, Phys. Rev. B 5:4541(1972).

36. S. Nohara, H. Namatame, A. Fujimori and T. Takabatake, to be published in Phys. Rev. B (1992).

37. T. Fujila, T. Suzuki, S. Nishigori, T. Takabatake, H. Fujii and J. Sakurai, J. Magn. Magn. Mater. 104-107:1415(1992).

38. S. Nishigori, H. Goshima, T. Suzuki, T. Fujita, G. Nakamoto, T. Takabatake, H. Fujii and J. Sakurai, to be published in Physica B (1992). 